\title{
Экстракционное разделение разнозарядных хлоридных комплексов иридия (IV) и родия (III) в расслаивающихся водных системах
}

\author{
(C) 2020 Симонова T.Н., Некрасова Е.А. \\ ГОУ ВПО «Донецкий наџиональный университет», Донецћк
}

Поступила в редакцию 25.03.2020 г.

DOI: $10.17308 /$ sorpchrom.2020.20/2785

Исследована экстракция хлоридных комплексов иридия (IV) и родия (III) в двухфазной водной системе (ДВС) без введения дополнительного реагента. Предложена двухфазная водная система (ДВС) полиэтиленгликоль (ПЭГ-1500, ПЭГ-115) - $\mathrm{NaCl}-\left(\mathrm{NH}_{4}\right)_{2} \mathrm{SO}_{4}-\mathrm{H}_{2} \mathrm{O}$ для избирательного извлечения иридия (IV) без введения дополнительного реагента. Цель работы - изучение закономерностей межфазного распределения хлоридных комплексов иридия (IV) и разработка экстракционного метода отделения его от родия (III) с применением ДВС. Квантово-химическими расчетами и методом экстракции показано влияние величины заряда на центральном атоме иона разнозарядных хлоридных комплексов иридия (IV) и родия (III) на межфазное распределение их в ДВС. Природа водорастворимого экстрагента влияет на полноту извлечения аналита из концентрированных сульфатных растворов. Хлоридный комплекс иридия (IV) практически полностью извлекается ПЭГ-1500, ПЭГ-115 на 95 \%; этанолом, изопропанолом (ИПС), ацетоном на 23, 11, 15\% соответственно. Хлоридный комплекс родия (III) извлекается ПЭГ на 4\% и не экстрагируется этанолом, ИПС и ацетоном. Состав экстрагируемого соединения установлен методом молекулярной абсорбционной спектрофотометрии. В спектре поглощения экстракта иридия (IV) на основе ПЭГ наблюдаются максимумы поглощения при 435 и 495 нм, характерные для комплекса $\left[\mathrm{IrCl}_{6}\right]^{2-}$. В спектрах поглощения водной фазы после отделения иридия (IV) наблюдаются полосы поглощения при длинах волн 412 и 518 нм, характерные для комплекса $\left[\mathrm{RhCl}_{6}\right]^{3-}$ . На основании проведенных исследований разработан экстракционный метод отделения иридия (IV) от родия (III) в виде разнозарядных хлоридных комплексов. Оптимизированы условия разделения иридия (IV) и родия (III) с использованием ПЭГ. Соотношение водной и органической фазы составляет 3 : 1. Максимальное извлечение хлоридного комплекса иридия (IV) и отделения его от родия (III) наблюдается при концентрации $\mathrm{C}\left(\mathrm{Cl}^{-}\right)=1.3 \cdot 10^{-2}-0.5$ моль/дм ${ }^{3}$. При разделении иридия (IV) и родия (III) coдержание аналитов вводной и органической фазах системы содержание аналитов определяют спектрофотометрическим методом по окраске $\left[\mathrm{IrCl}_{6}\right]^{2-}$ и $\left[\mathrm{RhCl}_{6}\right]^{3-}$. В оптимальных условиях экстракции иридий (IV) отделяется также от рутения (III), железа (III), алюминия (III), никеля (II), меди (II), кобальта (II), магния (II), цинка (II), свинца (II). Фактор разделения Ir (IV) / Rh (III) составляет 456. Методика разделения отличается простотой (экстракция в одну стадию), экономичностью, экспрессностью, применением малоопасного экстрагента ПЭГ, продолжительность - 20 мин.

Ключевые слова: экстракция, иридий (IV), родий (III), хлоридные комплексы, двухфазные водные системы, молекулярная абсорбционная спектрофотометрия.

\section{Введение}

Иридий и родий вследствие их химической инертности, особых физических свойств применяются в различных областях науки и техники. Иридий и родий сосуществуют в большинстве материалов, часто они мешают определению друг другу. Экстракционные методы разделения иридия и родия обычно входят в схему анализа 
[1]. Поиск альтернативных методов извлечения, разделения и определения платиновых металлов в процессе переработки вторичного сырья является важной аналитической задачей. Процессы вскрытия, разделения платиновых металлов, в том числе иридия и родия, часто проводят в солянокислых растворах. В технологических растворах иридий(IV), родий (III) образуют разнозарядные анионные комплексы $\left[\mathrm{IrCl}_{6}\right]^{2-}$, $\left[\mathrm{RhCl}_{6}\right]^{3-}$. В литературе описаны экстракционные методы разделения иридия(IV) и родия (III) три-н-бутилфосфатом, диантипирилпропилметаном в дихлорэтане, метилизобутилкетоном, три-н-октиламином в хлороформе и др. [1-3]. Недостатком этих методов является многостадийность и применение токсичных экстрагентов. Опасность экстрагентов можно снизить путем использования двухфазных водных систем (ДВС) на основе водорастворимых полимеров, спиртов, кетонов, удовлетворяющих принципам «зеленой» экстракции [4,5]. Перспективным направлением в ДВС является осуществление экстракции без введения дополнительных реагентов, что повышает экономичность, экспрессность экстракционных процессов [6]. Нами показана возможность экстракции хлоридных ацидокомплексов иридия(IV), отделения от родия(III) водорастворимыми экстрагентами [7].

Цель данной работы - изучение закономерностей межфазного распределения хлоридных комплексов иридия(IV) и отделения его от родия(III) с применение ДВС.

\section{Эксперимент}

Использовали этанол, изопропанол (ИПС), ацетон х.ч.; ПЭГ-1500 (Apply Chem, Germany); ПЭГ-115 (Реахим, ТУ 6-14 826-86); NaCl, (NH4)2 $\mathrm{SO}_{4}, \mathrm{HCl}, \mathrm{H}_{2} \mathrm{SO}_{4}$, х.ч. Pacтвор иридия(IV) $\left(1 \mathrm{~m} / \mathrm{cm}^{3}\right)$ готовили растворением навески $\mathrm{IrO}_{2} \cdot 2 \mathrm{H}_{2} \mathrm{O}$ при нагревании в $6 \mathrm{M} \mathrm{HCl}$, раствор родия(III) $\left(1 \mathrm{mг} / \mathrm{cm}^{3}\right)$ готовили растворением навески $\mathrm{K}_{3} \mathrm{RhCl}_{6}$ и $\mathrm{RhCl}_{3}$ в $1 \mathrm{M}$ растворе $\mathrm{HCl}$. Спектрофотометрические измерения проводили на фотоколориметре КФК-3, спектрофотометре СФ-2000. Кислотность растворов контролировали иономером И-160 МИ. Эксперимент проводили при комнатной температуре. Выбор высаливателя для извлечения иридия (IV) и родия (III) осуществляли в соответствии с рядом устойчивости комплексов платиновых металлов с неорганическим лигандом: $\mathrm{SO}_{4}{ }^{2-}<\mathrm{Cl}^{-}<\mathrm{Br}^{-}<\mathrm{SCN}^{-}<\mathrm{CN}^{-}$.

Для дальнейших исследований в качестве высаливателя был выбран насыщенный раствор $\left(\mathrm{NH}_{4}\right)_{2} \mathrm{SO}_{4}$ в связи с образованием наименее устойчивого сульфатного комплекса. Содержание иридия(IV) в равновесных фазах системы определяли спектрофотометрическим методом по собственной окраске [ $\mathrm{IrCl} 6]^{2-}$, родия(III) - спектрофотометрическим методом с $\mathrm{SnCl}_{2}$. Для выбора условий экстракции в делительную воронку вводили раствор иридия(IV) $\left(1\right.$ мг/см $\left.{ }^{3}\right)$, объем высаливателя $\left(\mathrm{NH}_{4}\right)_{2} \mathrm{SO}_{4}$, необходимый для расслаивания фаз. Кислотность водной фазы создавали добавлением $\mathrm{H}_{2} \mathrm{SO}_{4}$. Водную фазу разбавляли дистиллированной водой до $10 \mathrm{~cm}^{3}$, добавляли $5 \mathrm{~cm}^{3}$ экстрагента (этанол, ИПС, ацетон, ПЭГ). Установлено, что экстракционное равновесие достигается в течение 1 мин. Расслаивание фаз происходит при концентрации $\left(\mathrm{NH}_{4}\right)_{2} \mathrm{SO}_{4}$, равной 2.0-2.7 моль/дм ${ }^{3}$. Верхняя концентрационная граница обусловлена растворимостью соли в воде, нижняя - отсутствием разделения фаз. Соотношение водной и органической фаз составило $3: 1$, при котором объем органической фазы соответствует объему вводимого экстрагента.

\section{Обсуждение результатов}

В практике анализа наибольшее распространение получили хлоридные комплексы иридия(IV) и родия(III). На извлечение и разделение комплексных анионов 
значительное влияние оказывают заряд ацидокомплекса, тип координации лиганда, стерические и другие факторы [8,9]. Эффективность экстракции комплексов платиновых металлов жидкими анионообменниками зависит от отношения величины заряда к радиусу аниона [10]. С целью прогнозирования выбора эффективных экстрагентов в ДВС проведены квантово-химические расчеты величины заряда на центральном атоме иона для хлоридных комплексов некоторых платиновых и драгоценных металлов. Установлена линейная корреляция между коэффициентом распределения и величиной заряда [11]. Расчеты исследуемых комплексов с сосредоточенным зарядом были проведены с применением программы Hyper Chem и Морас-2009. Проведенные исследования послужили основой для разработки новой методики извлечения и отделения палладия в виде хлоридного комплекса от ВЗА рутения(III), родия(III) на основе ПЭГ с последующим спектрофотометрическим определением [12]. В продолжение проведенных исследований нами изучено межфазное распределение разнозарядных хлоридных комплексов иридия(IV) и родия(III) водорастворимыми экстрагентами (табл.1)

Таблица 1. Экстракция хлоридных комплексов иридия (IV) и родия (III) водорастворимыми экстрагентами $\mathrm{C}(\mathrm{Ir})=710^{-4}, \mathrm{c}(\mathrm{Rh})=1310^{-4}, \mathrm{C}(\mathrm{Cl})=0.25 ; \mathrm{C}\left(\mathrm{H}^{+}\right)=0.25 \mathrm{моль} / \mathrm{дm}^{3}$

\begin{tabular}{|c|c|c|c|c|c|}
\hline \multirow{2}{*}{$\mathrm{z}^{*}$} & \multicolumn{5}{|c|}{ Экстрагент } \\
\hline & ПЭГ-1500 & ПЭГ-115 & Этанол & ИПС & Ацетон \\
\hline$\left[\mathrm{IrCl}_{6}\right]^{2-}$ & 95 & 95 & 23 & 11 & 15 \\
\hline$\left[\mathrm{RhCl}_{6}\right]^{3-}$ & 4 & 4 & $\begin{array}{l}\text { не экстра- } \\
\text { гируется }\end{array}$ & $\begin{array}{c}\text { не экстраги- } \\
\text { руется }\end{array}$ & $\begin{array}{c}\text { не экстра- } \\
\text { гируется }\end{array}$ \\
\hline$\left[\mathrm{PdCl}_{4}\right]^{2-}$ & 98 [12] & 98 [12] & 40 [12] & 25 [12] & - \\
\hline
\end{tabular}

*z- заряд на центральном атоме иона

Хлоридные комплексы иридия(IV) извлекаются ПЭГ в присутствии высаливателя $\left(\mathrm{NH}_{4}\right)_{2} \mathrm{SO}_{4}$ на 95\% (табл. 1). Комплекс $\left[\mathrm{IrCl}_{6}\right]^{2-}$ в отличие от ПЭГ экстрагируется этанолом, ацетоном, ИПС на 23; $15 ; 11 \%$ соответственно. Различное поведение хлоридных комплексов аналита связано с условиями гидратации и сольватации в равновесных фазах системы. ПЭГ, содержащий согласно литературным данным 70\% воды, в большей степени экстрагирует гидратированное соединение чем, ИПС, содержание воды в органической фазе которого составляет $30 \%$. Аналогичное экстракционное поведение наблюдается для $\left[\mathrm{PdCl}_{4}\right]^{2-}[12]$. Следует отметить, что $\left[\mathrm{RhCl}_{6}\right]^{3-}$, для которого заряд на центральном атоме комплекса равен 0,05 , практически не извлекается водорастворимыми спиртами, ацетоном и ПЭГ (табл.1). Это является основой для разделения хлоридных комплексов иридия(IV) и родия(III) при помощи ПЭГ, который был выбран в качестве экстрагента для дальнейших исследований. Изучено влияние кислотности среды и концентрации хлорид-ионов. Максимальное извлечение иридия(IV) наблюдается в интервале концентраций $\mathrm{H}_{2} \mathrm{SO}_{4}$ 0.25-0.30 моль/дм ${ }^{3}$, обусловленный гидролизом соединений иридия (IV), конкурентной экстракцией $\mathrm{H}_{2} \mathrm{SO}_{4}$ (рис.1).

Иридий (IV) практически полностью извлекается ( $\mathrm{R}=95 \%)$ в интервале концентраций хлорид-ионов $1.3 \cdot 10^{-2}-5 \cdot 10^{-1}$ моль/дм ${ }^{3}$, обусловленном высокой устойчивостью комплекса $\left[\mathrm{IrCl}_{6}\right]^{2-}\left(\lg \beta{ }_{6}=31\right)[13]$.

Извлечение хлоридного комплекса иридия (IV) характеризуется переходом в органическую фазу ассоциата:

$$
\begin{gathered}
\mathrm{Kt}_{2}\left[\mathrm{IrCl}_{6}\right] \bullet(\mathrm{x}+\mathrm{m}) \mathrm{H}_{2} \mathrm{O}+\Pi \ni \Gamma \bullet \mathrm{k} \mathrm{H}_{2} \mathrm{O}+\left(\mathrm{NH}_{4}\right)_{2} \mathrm{SO}_{4} \bullet n \mathrm{H}_{2} \mathrm{O} \leftrightarrow \\
\leftrightarrow \mathrm{Kt}_{2}\left[\mathrm{IrCl}_{6}\right] \bullet \mathrm{y} \Pi Э \Gamma(\mathrm{k}+\mathrm{m}) \mathrm{H}_{2} \mathrm{O}+\left(\mathrm{NH}_{4}\right)_{2} \mathrm{SO}_{4} \bullet(\mathrm{n}+\mathrm{x}) \mathrm{H}_{2} \mathrm{O},
\end{gathered}
$$


где $\mathrm{Kt}-\mathrm{H}^{+}, \mathrm{NH}_{4}^{+}$.

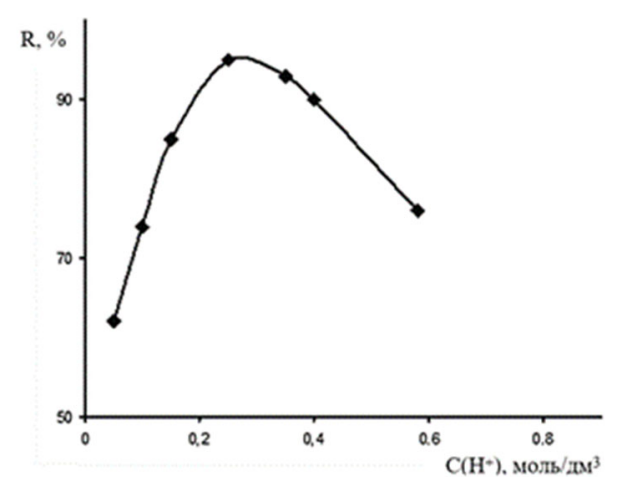

Рис. 1. Зависимость степени извлечения иридия (IV) от кислотности водной фазы $\left(\mathrm{c}(\operatorname{Ir}(\mathrm{IV}))=7 \cdot 10^{-4}\right.$, $\mathrm{c}\left(\mathrm{Cl}^{-}\right)=0.25$ моль/дм $\left.{ }^{3}\right)$

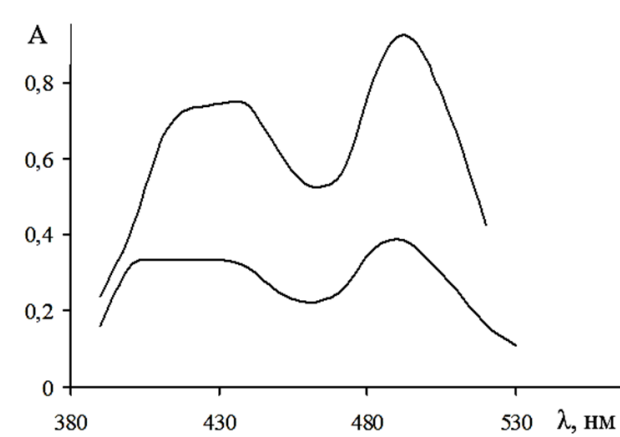

Рис. 2. Спектры поглощения хлоридных комплексов иридия (IV): 1 - органическая фаза. (ПЭГ-1500); 2 - водная фаза. $\left(\mathrm{C}(\mathrm{Ir}(\mathrm{IV}))=7 \cdot 10^{-4}\right.$, $\mathrm{C}\left(\mathrm{Cl}^{-}\right)=0.25, \mathrm{C}\left(\mathrm{H}^{+}\right)=0.25$ моль $/$ дм $\left.^{3}\right)$

В спектре поглощения экстракта иридия(IV) при помощи ПЭГ наблюдаются максимумы поглощения при $\lambda=435$ и $495 \mathrm{Hм}$, характерные для $\left[\mathrm{IrCl}_{6}\right]^{2-}$ в водных растворах (рис. 2) [13].

Увеличение оптической плотности экстракта в 3 раза по сравнению с водной фазой обусловлено абсолютным концентрированием. В оптимальных условиях экстракции иридия(IV) проведены спектрофотометрические исследования водной фазы, содержащей родий (III), после отделения органической фазы, содержащей $[\mathrm{IrCl} 6]^{2-}$. В спектре поглощения водной фазы после экстракции наблюдаются полосы поглощения при длинах волн 412 и 518 нм, которые совпадают с максимумом поглощения координационно-насыщенного комплекса $\left[\mathrm{RhCl}_{6}\right]^{3-}$ в водной фазе [13].

На основании проведенных исследований разработан способ экстракционного отделения иридия(IV) от родия(III) в виде разнозарядных ацидокомплексов $[\mathrm{IrCl} 6]^{2-}$ и $\left[\mathrm{RhCl}_{6}\right]^{3-}$. В оптимальных условиях при концентрации хлорид-ионов и ионов водорода, равных 0,25 моль/дм³, соотношении водной и органической фаз 3:1, концентрации с $\left(\left(\mathrm{NH}_{4}\right)_{2} \mathrm{SO}_{4}\right)=2.7$ моль/дм ${ }^{3}$ иридий $(\mathrm{IV})$ извлекается на $95 \%$, родий(III) $-4 \%$. Содержание иридия(IV) определяют спектрофотометрическим методом по окраске $\left[\mathrm{IrCl}_{6}\right]^{2-}$ при $\lambda=495$ нм. Содержание родия(III) определяют в водной фазе после экстракции спектрофотометрическим методом с $\mathrm{SnCl}_{2}$ и по окраске $\left[\mathrm{RhCl}_{6}\right]^{3-}$. Фактор разделения для иридия (IV) и родия (III) составляет 456. Метод отличается простотой и экспрессностью (однократная экстракция в течение 2 минут), экономичностью и применением малоопасного экстрагента ПЭГ.

\section{Заключение}

Предложена экстракционная система (ПЭГ-1500, ПЭГ-115) - $\left(\mathrm{NH}_{4}\right)_{2} \mathrm{SO}_{4}-\mathrm{H}_{2} \mathrm{O}$ для экстракционного разделения иридия (IV) и родия (III) на основе разнозарядных хлоридных комплексов. Экстракционное поведение хлоридных комплексов иридия (IV), родия (III) наряду с другими факторами определяется отношением величины заряда комплекса к его радиусу. По экстракционной способности водорастворимые экстрагенты хлоридных комплексов иридия (IV) в присутствии высаливателя $\left(\mathrm{NH}_{4}\right)_{2} \mathrm{SO}_{4}$ располагают в ряд: ПЭГ-1500, ПЭГ-115>ацетон>этанол>ИПС. Установлены оптимальные условия экстракционного извлечения $\left[\mathrm{IrCl}_{6}\right]^{2-}$ и отделения от 
$\left[\mathrm{RhCl}_{6}\right]^{3-}$ из концентрированных сульфатных растворов при помощи ПЭГ. Методом молекулярной абсорбционной спектрофотометрии показано, что в органической фазе наблюдаются полосы поглощения при длинах волн 435 и 495 нм, характерные для $[\mathrm{IrCl} 6]^{2-}$ в водных растворах. В этих условиях родий (III) практически не извлекается ПЭГ и остается в водной фазе, в которой наблюдаются полосы поглощения при $\lambda=412$ и $518 \mathrm{Hм}$, характерные для $\left[\mathrm{RhCl}_{6}\right]^{3-}$. Разработан ускоренный метод отделения иридия (IV) от родия (III) на основе аналитических форм разнозарядных хлоридных комплексов. Метод отличается простотой, экологической безопасностью, экономичностью.

\title{
Список литературы
}

1. Гинзбург С.И. и др. Аналитическая химия платиновых металлов. М. Наука. 1972. $613 \mathrm{c}$.

2. Al-Bazi S. J., Chow A. // Talanta. 1984. Vol. 31. №10A. pp.815-836.

3. Золотов Ю.А., Варшал Г.М., Иванов В.М. Аналитическая химия металлов платиновой группы: Сб. обзорных статей. М. Едиториал УРСС. 2003. 592 с.

4. Anastas P.T., Warner J.C. // NewYork: Oxford University Press. 1998. $144 \mathrm{p}$.

5. Armenta S., Garrigues S., DelaGuardia M. // Trends in Anal. Chem. 2015.Vol. 71. No 9. pp. 2-8.

6. Rogers R.D., Bond A.H., Bauer C.B. // Sep. Sci. Technol. 1993. Vol. 28. No 5. pp.10911126.

7. Симонова Т.Н., Дубровина В.А., Некрасова Е.А. // Материаль ІІІ Всероссийского симпозиума «Разделение и концентрирование в аналитической химии и радиохимии». Краснодар, 2011. С.83.
8. Шевчук И.А. Экстракция органическими основаниями. Киев. Вища школа. 1978. $172 \mathrm{c}$.

9. Шевчук И.А., Симонова Т.Н. Экстракция соединений цветных и редких металлов из карбонатных, серусодержащих и галогенидных растворов. Донецк. ДонГУ. 1999. 215 c.

10. С.С. Колекар, Анюс М.А. // Журнал аналитической химии. 2002, Т. 57. № 12. С. 1257-1261.

11. Дубровина В.О. Автореф. дис. канд. хім. наук. Одесса. 2013. 22 с.

12. Симонова Т.Н., Дубровина В.А. // Вестник ВГУ, серия: Биология. Фармация. 2018. № 4. C. 44-49.

13. Буслаева Т.М., Умрейко Д.С., Новицкий Г.Г. и др. Химия и спектроскопия галогенидов платиновых металлов. Минск. Университетское. 1990. 279 с.

\section{Extraction by separation of multi-charge chloride complexes of iridium (IV) and rhodium (III) in segregated water systems}

\author{
(C) 2020 Simonova T.N., Nekrasova E.A. \\ Donetsk National University, Donetsk
}

\begin{abstract}
Extraction of iridium (IV) and rhodium (III) chloride complexes in a two-phase water system without the introduction of an additional reagent was studied. A polyethylene glycol (PEG-1500, PEG-115) - NaCl $\left(\mathrm{NH}_{4}\right)_{2} \mathrm{SO}_{4}-\mathrm{H}_{2} \mathrm{O}$ two-phase water system is proposed for the selective extraction of iridium (IV) without the introduction of an additional reagent. The purpose of this work was to study the regularities of the interphase distribution of iridium (IV) chloride complexes and to develop an extraction method for its separation from rhodium (III) using a two-phase water system. The quantum-chemical calculations and the extraction method showed the influence of charge value on the central atom of the ion of multi-charge chloride complexes of iridium (IV) and rhodium (III) on their interphase distribution in a two-phase water system. The nature of the water-soluble extractant affected the completeness of the analyte extraction from the concentrated sulphate solutions. The iridium (IV) chloride complex was almost completely extracted with PEG-1500, PEG-115 by $95 \%$ and was extracted with ethanol, isopropanol (IPA), and acetone by 23,11 , and $15 \%$ respectively. The
\end{abstract}


rhodium (III) chloride complex was extracted with PEG by $4 \%$ and was not extracted with ethanol, IPA, or acetone. The composition of the extracted compound was determined by molecular absorption spectrophotometry. Absorption maximums typical for the $\left[\mathrm{IrCl}_{6}\right]^{2-}$ complex were observed at 435 and $495 \mathrm{~nm}$ in the PEGbased absorption spectrum of the iridium (IV) extract. After the separation of iridium (IV), absorption bands were observed in the absorption spectra of the aqueous phase at wavelengths of 412 and $518 \mathrm{~nm}$, which are characteristic of the $\left[\mathrm{RhCl}_{6}\right]^{3-}$ complex. As a result of the conducted studies, an extraction method was developed for the separation of iridium (IV) from rhodium (III) in the form of the multi-charge chloride complexes. Optimal conditions for the separation of iridium (IV) from rhodium (III) using PEG were determined. The ratio of the aqueous phase to the organic phase is $3: 1$. Maximum extraction of the iridium (IV) chloride complex and its separation from rhodium (III) was observed with the concentration of $\mathrm{C}\left(\mathrm{Cl}^{-}\right)=1.3 \cdot 10^{-2}-0.5 \mathrm{~mol} / \mathrm{dm}^{3}$. When the iridium (IV) is separated from rhodium (III), the composition of the analytes in the aqueous and organic phases was determined by a spectrophotometric method based on the colour of $\left[\mathrm{IrCl}_{6}\right]^{2-}$ and $\left[\mathrm{RhCl}_{6}\right]^{3-}$. Under optimal extraction conditions, iridium (IV) has also been separated from ruthenium (III), iron (III), aluminum (III), nickel (II), copper (II), cobalt (II), magnesium (II), zinc (II), and lead (II). The Ir (IV) / Rh (III) separation factor is 456 . The separation technique is characterised by its simplicity (single stage extraction), cost effectiveness, rapidity, and the use of a low-risk PEG extractant. The process takes 20 minutes.

Keywords: extraction, iridium (IV), rhodium (III), chloride complexes, two-phase water systems, molecular absorption spectrophotometry.

\section{References}

1. Ginzburg S.I. et al. Analiticheskaya khimiya platinovykh metallov, M., Nauka, 1972, 613 p.

2. Al-Bazi S.J., Chow A., Talanta, 1984, Vol. 31, No 10A, pp.815-836.

3. Zolotov Yu.A., Varshal G.M., Ivanov V.M.. Analiticheskaya khimiya metallov platinovoi gruppy: Sb. obzornykh statei. M.. Editorial URSS. 2003. 592 p.

4. Anastas P.T., WarnerJ.C., NewYork: Oxford University Press, 1998, 144 p.

5. Armenta S., Garrigues S., DelaGuardia M., Trends in Anal. Chem., 2015, Vol. 71, No 9, pp. 2-8.

6. Rogers R.D., Bond A.H., Bauer C.B., Sep. Sci. Technol., 1993, Vol. 28, No 5, pp.10911126.

7. Simonova T.N., Dubrovina V.A., Nekrasova E.A., Materialy III Vserossiiskogo simpoziuma «Razdelenie $i$ kontsentrirovanie $v$ analiticheskoi khimii $i$ radiokhimii», Krasnodar, 2011, p.83.

Симонова Тамара Николаевна - к.Х.Н., доцент кафедры аналитической химии, Донецкий национальный университет, Донецк

Некрасова Е.А. - магистрант кафедры аналитической химии, Донецкий национальный университет, Донецк
8. Shevchuk I.A., Ekstraktsiya organicheskimi osnovaniyami, Kiev, Vishcha shkola, 1978, $172 \mathrm{p}$.

9. Shevchuk I.A., Simonova T.N., Ekstraktsiya soedinenii tsvetnykh i redkikh metallov iz karbonatnykh, serusoderzhashchikh i galogenidnykh rastvorov, Donetsk, DonGU, 1999, 215 p.

10. Kolekar S.S., Anyus M.A., Zhurnal analiticheskoi khimii, 2002, Vol. 57, No 12, pp. 1257-1261.

11. Dubrovina V.O. Avtoref. dis. kand. khim. Nauk, Odessa, 2013, 22 s.

12. Simonova T.N., Dubrovina V.A., Vestnik $V G U$, seriya: Biologiya. Farmatsiya, 2018, No 4, pp. 44-49.

13. Buslaeva T.M., Umreiko D.S., Novitskii G.G. et al., Khimiya i spektroskopiya galogenidov platinovykh metallov, Minsk, Universitetskoe, 1990, 279 p.

Simonova Tamara N. - Ph.D. (chemistry), associate professor, department of analytical chemistry, Donetsk National University, Donetsk, Email: simonovatn@yandex.ru

Nekrasova E.A. - master analytical chemistry department, Donetsk National Uneversity, Donetsk 